\title{
Influence of skirt reinforcement in passive zone on deformation of excavation
}

\author{
Peng-fei CHEN ${ }^{1 a^{*}}$, Xiao-nan GONG ${ }^{1}$ \\ ${ }^{1}$ Research Center of Coastal and Urban Geotechnical Engineering, Zhejiang University, Hangzhou, China
}

\begin{abstract}
In the design of the excavation protection scheme in the soft soil area, it is often necessary to set up cement-soil mixing piles in the passive area. In this way, the stability requirements of the excavation can be met, and the lateral displacement of the retaining pile can be greatly restricted. This paper uses PLAXIS 3D to establish a excavation model in a soft area, and discusses the influence of various parameters of the passive zone mixing pile on the deformation and force of the excavation. Within a certain range, as the cohesive force or secant modulus or reinforcement width or depth of the reinforcement area increases, the lateral displacement and settlement outside the pit will decrease. But when it exceeds a certain range, the decreasing trend becomes very slow. With the increase of the four parameters of the reinforcement zone, bending moments in opposite directions appear below the bottom of the excavation. Moreover, the value of the bending moment is getting larger and larger. Therefore, considering the force, it is not that the wider and deeper the reinforced zone is, the more advantageous is.
\end{abstract}

\section{Introduction}

In soft soil foundation, when the surrounding environmental protection requirements are high, mixing piles and high-pressure jet grouting piles are often used to reinforce the soil in the passive zone before the excavation of the excavation ${ }^{1}$. The purpose is to improve the resistance of the soil in the passive zone and reduce the deformation of the retaining structure during the excavation of the excavation ${ }^{2}$. The way of skirt reinforcement is an arrangement with better reinforcement effect.

Ma Yun ${ }^{3}$ combined with a typical excavation in Wuhan, comparative analysis of both numerical simulation study and on-site monitoring. The influence of the reinforcement parameters of the passive zone of the excavation in the weak soil area on the displacement of the supporting structure is analyzed. The influence of the depth, width, shape and other parameters of the reinforced area on the displacement of the supporting structure is discussed.

Zheng Junjie ${ }^{4}$ used numerical simulation methods and random field theory to focus on the influence of the strong spatial variability of parameters in the passive reinforcement area on the overall deformation behavior of soft soil deep excavations and their laws.

Liu $\mathrm{Yi}^{5}$ selected different reinforced soil parameters and used the HS (hardening-soil) finite element model under the condition of soil unloading to analyze the influence of passive zone reinforcement on the deformation of super large deep excavations.

\section{Engineering background and model establishment}

The proposed construction on the plot mainly includes a 15-story office building and an attached 3-story commercial building. There are 3 floors of basement. The proposed building is a frame structure with a bored pile foundation. The designed maximum single column load is about $2500 \mathrm{KN}$. There are subway pipelines and residential buildings around the excavation. The development of underground space in the narrow site of the old city is very risky, and the lateral deformation of the retaining wall needs to be strictly controlled. Considering comprehensively, the enclosure plan of the excavation project uses cast-in-place piles as retaining piles, cementsoil mixing piles as water-stop curtains, and cement-soil mixing piles for reinforcement in the passive area of the excavation, and reinforced concrete as strut.

The soil range of the PLAXIS 3D model is a square with a side length of $200 \mathrm{~m}$ and the soil depth is $50 \mathrm{~m}$. Choose the hardened soil model ${ }^{6}$. Take the average of each parameter, such as gravity $\gamma=18.5 \mathrm{KN} / \mathrm{m}^{3}$, cohesion $c=20 \mathrm{kPa}$, internal friction angle $\varphi=20^{\circ}$, secant modulus $E_{50}=10 \mathrm{MPa}, \mathrm{E}_{\mathrm{eod}}=10 \mathrm{MPa}, \mathrm{E}_{\mathrm{ur}}=$ $60 M \mathrm{~Pa}$, Poisson ratio $v=0.25$. The excavation is $100 \mathrm{~m}$ long, $50 \mathrm{~m}$ wide and $15 \mathrm{~m}$ deep. The enclosure structure is a bored pile with a length of $25 \mathrm{~m}$ and an embedded depth

${ }^{1}$ Corresponding author: 21212003@zju.edu.cn 
of $10 \mathrm{~m}$. The pile diameter of the cast-in-place pile is $1 \mathrm{~m}$, and the pile center distance is $1.5 \mathrm{~m}$. Because the pile center distance is small, and each layer is connected by crown beams or waist beams, the integrity is good. It can be converted into a diaphragm wall according to the equivalent stiffness method. The equivalent thickness of the diaphragm wall is calculated to be $0.732 \mathrm{~m}$. There are 3 layers of strut, respectively at depths of $0 \mathrm{~m},-5 \mathrm{~m}$, and $10 \mathrm{~m}$. Both the cast-in-place pile and the strut are concrete structures, with elastic modulus $E=30 G \mathrm{~Pa}$ and Poisson ratio $v=0.15$. The cement-soil mixing pile in the passive zone is simulated by solid elements, gravity $\gamma=$ $20 \mathrm{KN} / \mathrm{m}^{3}$, cohesion $\mathrm{c}=300 \mathrm{kPa}$, internal friction angle $\varphi=25^{\circ}$, secant modulus $E_{50}^{r e f}=320 \mathrm{MPa}, E_{\text {oed }}^{r e f}=$ $320 \mathrm{MPa}, E_{u r}^{r e f}=960 \mathrm{MPa}$, Poisson ratio $v=0.2$. The width of the skirt reinforcement is $\mathrm{B}=9 \mathrm{~m}$, and the depth $\mathrm{H}=6 \mathrm{~m}$. Set this model as the benchmark model. The variables discussed below are all changed in a single variable on this benchmark model, and other parameters remain unchanged.

A model is established based on the above data. The deformation calculation results and measured data of the envelope structure are shown in figure 1. It can be seen from the figure that if the reinforcement of the passive zone is not considered, the lateral displacement of the retaining pile is very large, close to $47 \mathrm{~mm}$, which exceeds the maximum lateral displacement allowed by the code. The calculated results considering the reinforcement of the passive zone are very close to the measured results. The measured value above the depth of $-15 \mathrm{~m}$ (the bottom of the excavation) is slightly smaller than the calculated value, and the measured value below the depth of $-15 \mathrm{~m}$ is slightly larger than the calculated value. The maximum value of both is about $23 \mathrm{~mm}$. It can be seen that this model is relatively close to the actual situation, and this can be used as a benchmark for discussion.

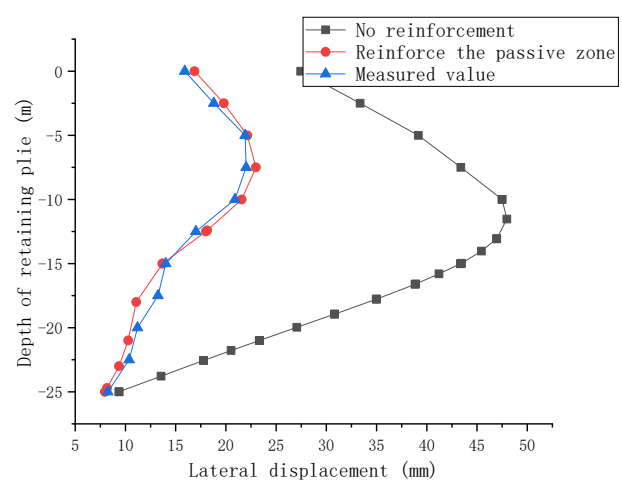

Fig. 1. Comparison of measured value and calculated value.

\section{Influence of constitutive parameters of mixing pile on excavation}

Check the excavation engineering manual ${ }^{1}$, the cohesive force $\mathrm{c}$ of the mixing pile is between $100 \mathrm{kPa}$ and $1100 \mathrm{kPa}$, the internal friction angle $\varphi$ is between $20^{\circ}$ and $30^{\circ}$, and ${ }^{6}$ the secant modulus $E_{50}$ is between $40 \mathrm{MPa}$ and $600 \mathrm{MPa}$. Because the range of $\varphi$ change is small, this article does not discuss the influence of the change of $\varphi$ value on the deformation of the excavation. Only discuss the influence of $\mathrm{c}$ and $E_{50}$.

\subsection{The influence of cohesion}

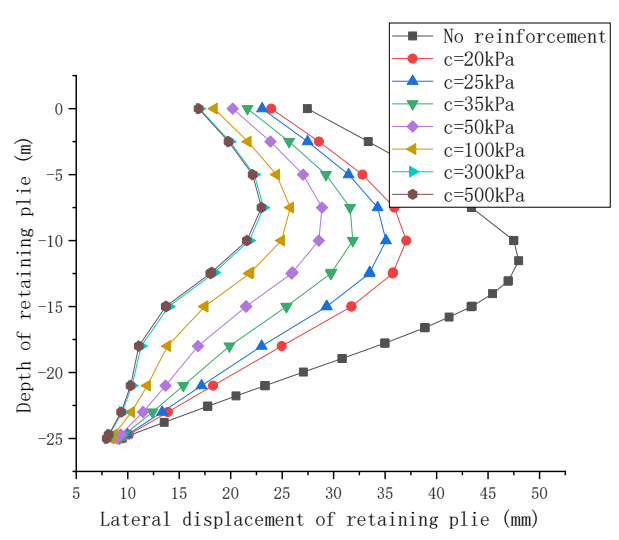

Fig. 2. The influence of cohesion on deformation Figure 2 is the relationship between the lateral displacement of the retaining pile and the cohesion of the mixing pile. It can be seen that the reinforcement of the passive zone can quickly reduce the lateral displacement. Even when the cohesion force of the mixing pile $c=$ $20 \mathrm{kPa}$ is relatively small (note that the secant modulus is taken as the data in the reference model), it is also very obvious, the reduction is about $10 \mathrm{~mm}$. When $\mathrm{c}$ increases from $20 \mathrm{kPa}$ to $300 \mathrm{kPa}$, the lateral displacement gradually decreases, from $37 \mathrm{~mm}$ to $23 \mathrm{~mm}$. When $\mathrm{c}$ is greater than $300 \mathrm{kPa}$, the increase of c has basically no effect on the deformation. In addition, the position of the maximum lateral displacement moved upward as the value of c increased, from $-12.5 \mathrm{~m}$ (without reinforcement) to $7.5 \mathrm{~m}(c=300 \mathrm{kPa})$.

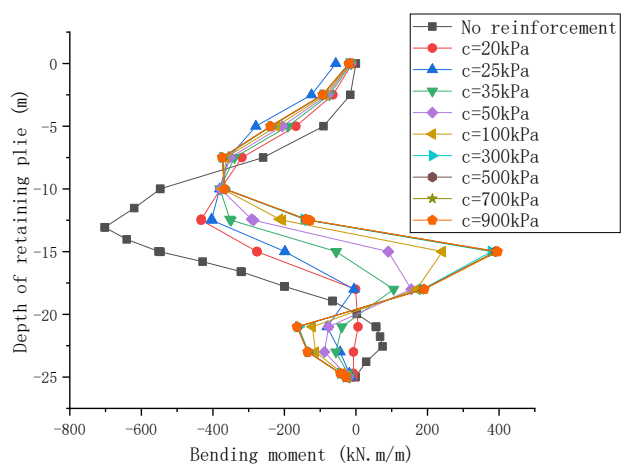

Fig. 3. The influence of cohesion on bending moment

Figure 3 is the relationship between the bending moment of the retaining pile and the cohesion $\mathrm{c}$ of the mixing pile. In the range of depth $0 \mathrm{~m}$ to $-10 \mathrm{~m}$, all curves basically coincide. The cohesive force $\mathrm{c}$ of the mixing pile basically has no effect on bending moment of the retaining pile. In the range of the depth $-10 \mathrm{~m}$ to $-14 \mathrm{~m}$, as the c value of the mixing pile increases, the bending moment of the retaining pile gradually decreases, but the direction of the bending moment is consistent. In the range of depth $-14 \mathrm{~m}$ to $-21 \mathrm{~m}$, the bending moment changed in direction. And as the value of $\mathrm{c}$ increases, the maximum bending moment 
in this range is gradually increasing, but the bending moment has reached its limit value, and the curve has overlapped. In the range of depth $-21 \mathrm{~m}$ to $-25 \mathrm{~m}$, the bending moment of the reinforced retaining pile and the unreinforced retaining pile are basically symmetrically distributed, and the values are not large.

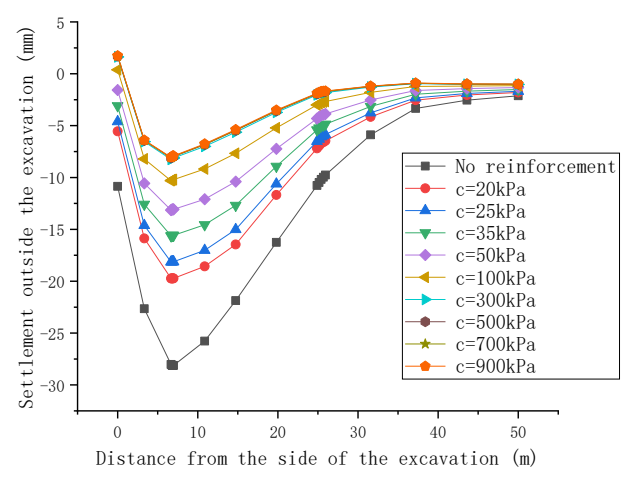

Fig. 4. The influence of cohesion on settlement

Figure 4 is the relationship between settlement and the cohesion $\mathrm{c}$ of the mixing pile. It can be seen that the reinforcement of the passive zone can quickly reduce the settlement. Even when the cohesive force of the mixing pile $c=20 \mathrm{kPa}$ is relatively small (note that the secant modulus is taken as the data in the benchmark model), this effect is also obviously, the reduction is about $8.5 \mathrm{~mm}$. When $\mathrm{c}$ increases from $20 \mathrm{kPa}$ to $300 \mathrm{kPa}$, the settlement gradually decreases, from $28 \mathrm{~mm}$ to $8 \mathrm{~mm}$. When $\mathrm{c}$ is greater than $300 \mathrm{kPa}$, the increase of c has little effect on settlement. In addition, the settlement occurred at $7.5 \mathrm{~m}$ away from the edge of the pit, that is, the $\mathrm{c}$ value has no effect on the maximum settlement position.

In fact, after the mixing pile is hardened, the cohesive force $\mathrm{c}$ is basically greater than $100 \mathrm{kPa}$. In real engineering the $\mathrm{c}$ value of the hardened mixing pile has little effect on the deformation of the excavation.

\subsection{The influence of secant modulus}

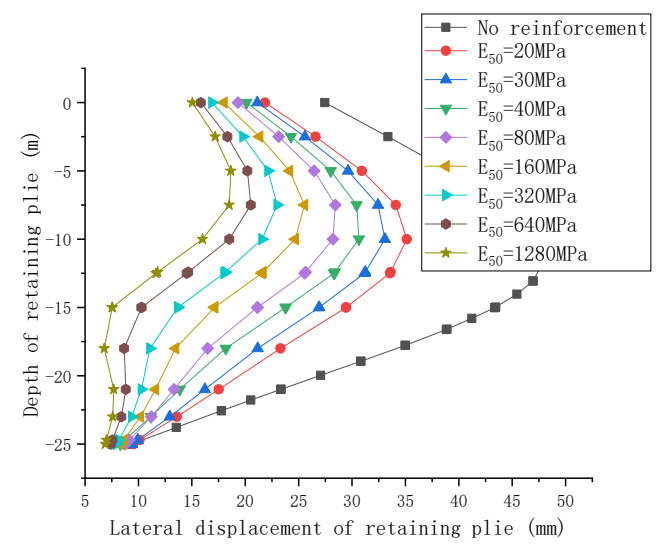

Fig. 5. The influence of secant modulus on lateral displacement Figure 5 is the relationship between the lateral displacement of the retaining pile and the secant modulus of the mixing pile. It can be seen that the reinforcement of the passive zone can quickly reduce the lateral displacement, even when the secant modulus of the mixing pile $E_{50}=20 \mathrm{Mpa}$ is relatively small (note that the cohesive force is taken as the data in the reference model), this effect is also very obvious, the reduction is about $12 \mathrm{~mm}$. When $E_{50}$ increases from $40 \mathrm{MPa}$ to $1280 \mathrm{MPa}$, the lateral displacement gradually decreases, from $31 \mathrm{~mm}$ to $19 \mathrm{~mm}$. Moreover, every time the $E_{50}$ doubles, the lateral displacement decreases by $2.4 \mathrm{~mm}$, which is relatively uniform. In addition, the position of the maximum lateral displacement moved up with the increase of the $E_{50}$ value, from $-12.5 \mathrm{~m}$ (no reinforcement) to $-7.5 \mathrm{~m}\left(E_{50}=1280 \mathrm{MPa}\right)$.

According to reports 1 , the secant modulus of mixing piles in other countries can reach a higher level. In the above-mentioned research range of this paper, the influence of the secant modulus $E_{50}$ on the lateral displacement of the retaining pile has not reached its limit value. Therefore, it is worth continuing to study the higher value of $E_{50}$.

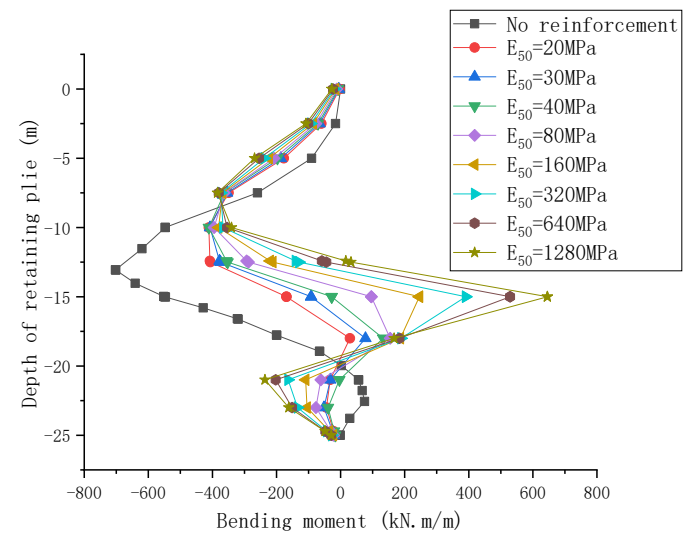

Fig. 6. The influence of secant modulus on bending moment

Figure 6 is the relationship between the bending moment of the retaining pile and the secant modulus $E_{50}$ of the mixing pile. Within the range of strut (that is, the depth of $0 \mathrm{~m}$ to $-10 \mathrm{~m}$ ), all the curves basically coincide. The secant modulus $E_{50}$ of the mixing pile has basically no effect on the bending moment of the surrounding pile within this range. In the range of $-10 \mathrm{~m}$ to $-12.5 \mathrm{~m}$ in depth, as the $E_{50}$ increases, the bending moment gradually decreases. But the direction of the bending moment in this range is consistent. In the depth range of $-12.5 \mathrm{~m}$ to $-21 \mathrm{~m}$, the bending moment of the retaining pile reinforced by the mixing pile and the bending moment of the non-reinforced retaining pile changed direction. And as the value of $E_{50}$ increases, the maximum bending moment is gradually increasing, and there is no limit value. In the depth of $21 \mathrm{~m}$ to $-25 \mathrm{~m}$, the bending moment of the reinforced retaining pile and the unreinforced retaining pile are basically symmetrically distributed, and the values are not large.

Figure 7 is the relationship between settlement and secant modulus E50 of the mixing pile. It can be seen that the reinforcement of the passive zone can quickly reduce the settlement, even when the secant modulus of the mixing pile $\mathrm{E}_{50}=20 \mathrm{Mpa}$ is relatively small (note that the cohesion force is taken as the data in the benchmark model), this effect is also Obviously, the reduction is about 
$10 \mathrm{~mm}$. When $\mathrm{E}_{50}$ increases from $40 \mathrm{Mpa}$ to $1280 \mathrm{Mpa}$, the sedimentation gradually decreases, from $18 \mathrm{~mm}$ to $5 \mathrm{~mm}$. In addition, the maximum soil settlement outside the pit occurred at $7.5 \mathrm{~m}$ from the side of the pit. That is, the $\mathrm{E}_{50}$ value has no effect on the maximum settlement position.

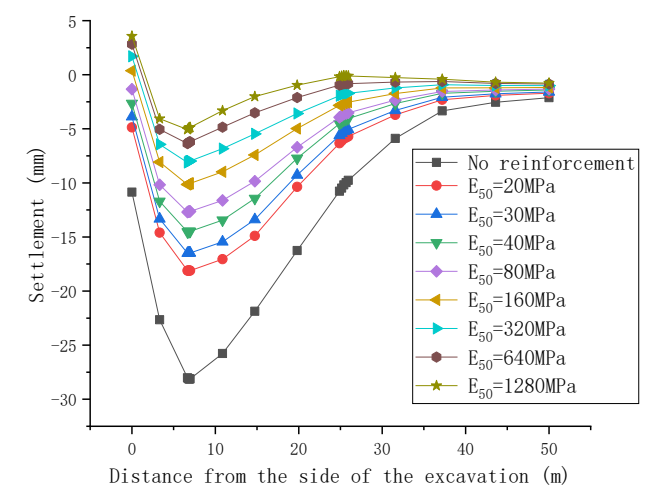

Fig. 7. The influence of secant modulus on settlement

\section{The influence of geometric parameters on excavation}

\subsection{The influence of reinforcement width $B$}

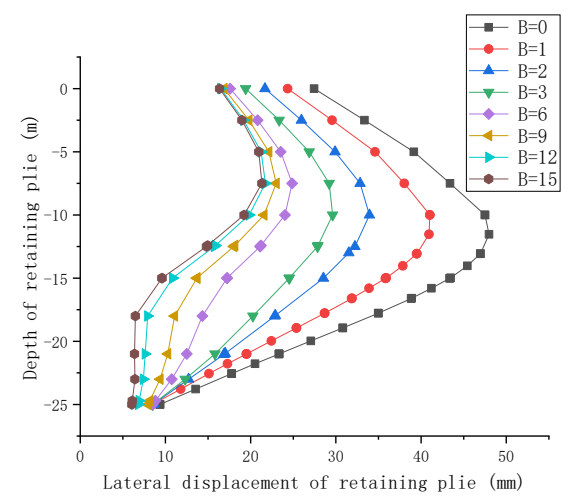

Fig. 8. The influence of width on lateral deformation Figure 8 is the relationship between the lateral deformation of the retaining pile and the reinforcement width $\mathrm{B}$ of the passive zone. It can be seen that when the reinforcement width is increased from $B=0 \mathrm{~m}$ (no reinforcement) to $B=6 \mathrm{~m}$, the lateral displacement of the retaining pile is significantly reduced, from $48 \mathrm{~mm}$ to $25 \mathrm{~mm}$, a $23 \mathrm{~mm}$ reduction. When $\mathrm{B}$ increases from $6 \mathrm{~m}$ to $12 \mathrm{~m}$, the lateral displacement of the retaining pile decreases, but the decrease is relatively small, only from $23 \mathrm{~mm}$ to $21 \mathrm{~mm}$. When B increases from $12 \mathrm{~m}$ to $15 \mathrm{~m}$, the curves basically coincide. Considering the deformation, $\mathrm{B}=3 \mathrm{~m}$ or $\mathrm{B}=6 \mathrm{~m}$ is a reasonable choice.

Figure 9 is the relationship between the bending moment of the retaining pile and the width $\mathrm{B}$ of the reinforcement area. It can be seen that from $B=0 m$ to $\mathrm{B}=3 \mathrm{~m}$, the shape of the bending moment curve is basically the same, and the value of the bending moment is gradually decreasing. From $B=6 m$ to $B=15 m$, there is a bending moment value below the bottom of the excavation that is opposite to the bending moment when it is not reinforced $(B=0)$, and the value is basically symmetrical. If considering the force, $\mathrm{B}=3 \mathrm{~m}$ is a relatively reasonable choice.

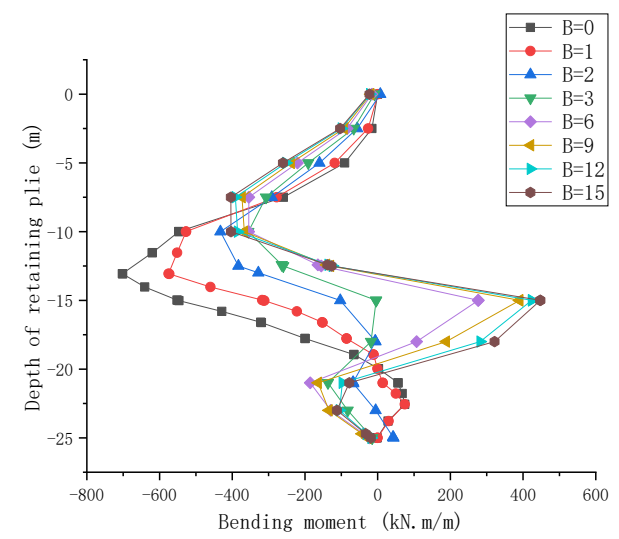

Fig. 9. The influence of width on bending moment

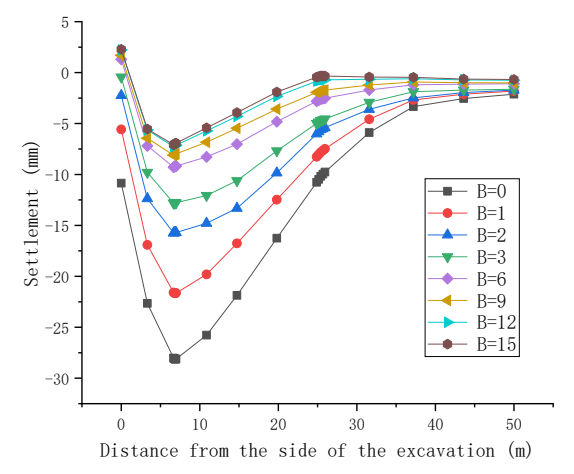

Fig. 10. The influence of width on settlement

Figure 10 shows the relationship between settlement and the reinforcement width $\mathrm{B}$ of the passive zone. It can be seen that when the reinforcement width of the skirt is increased from $\mathrm{B}=0 \mathrm{~m}$ (without reinforcement) to $\mathrm{B}=6 \mathrm{~m}$, the settlement is significantly reduced, from $28 \mathrm{~mm}$ to $9 \mathrm{~mm}$, a decrease of $17 \mathrm{~mm}$. When B increases from $6 \mathrm{~m}$ to $12 \mathrm{~m}$, the settlement decreases, but the amount of decrease is relatively small, only from $9 \mathrm{~mm}$ to $7 \mathrm{~mm}$. When B increases from $12 \mathrm{~m}$ to $15 \mathrm{~m}$, the curves basically coincide, that is to say, the influence of the increase of B on settlement can be ignored. Considering the settlement, $\mathrm{B}=3 \mathrm{~m}$ or $\mathrm{B}=6 \mathrm{~m}$ is a reasonable choice.

\subsection{Influence of reinforcement depth $\mathrm{H}$}

Figure 11 is the relationship between the lateral displacement of the retaining pile and the reinforcement depth $\mathrm{H}$ of the passive zone. It can be seen that when the reinforcement depth is increased from $\mathrm{H}=0 \mathrm{~m}$ ( no reinforcement) to $\mathrm{H}=4 \mathrm{~m}$, the lateral displacement of the retaining pile is significantly reduced, from $48 \mathrm{~mm}$ to $25.5 \mathrm{~mm}$, which is a reduction of $22.5 \mathrm{~mm}$. When $\mathrm{H}$ increases from $4 \mathrm{~m}$ to $10 \mathrm{~m}$, the lateral displacement of the retaining pile decreases, but the amount of decrease 
is relatively small, only from $25.5 \mathrm{~mm}$ to $21 \mathrm{~mm}$, a decrease of $4.5 \mathrm{~mm}$. Considering the deformation, $\mathrm{H}=4 \mathrm{~m}$ is a reasonable choice.

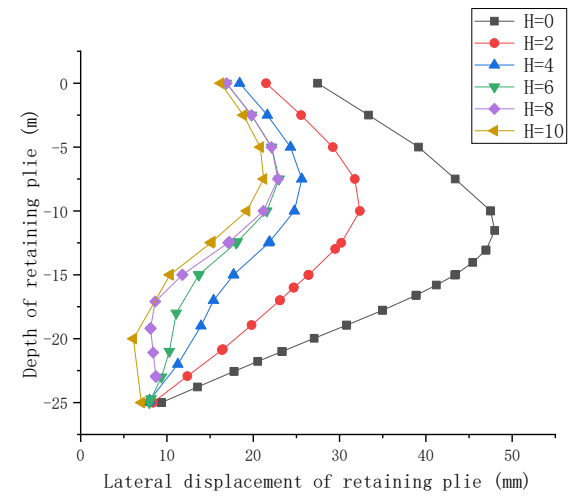

Fig. 11. The influence of depth on lateral displacement

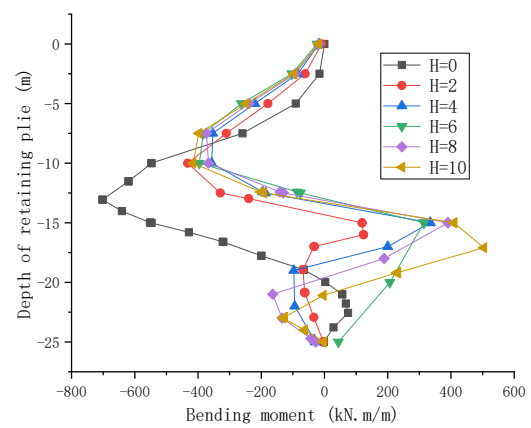

Fig. 12. The influence of depth on bending moment

Figure 12 is the relationship between the bending moment of the retaining pile and the reinforcement depth $\mathrm{H}$ of the passive zone. It can be seen that from $\mathrm{H}=4 \mathrm{~m}$ to $\mathrm{H}=10 \mathrm{~m}$, the bending moment below the bottom of the excavation has a bending moment value opposite to that of the unreinforced $(\mathrm{H}=0)$, and the value is basically symmetrical. $\mathrm{H}=2 \mathrm{~m}$, the positive and negative bending moment values of the retaining pile are basically equal, and the absolute value is small. If considering the force, $\mathrm{H}=2 \mathrm{~m}$ is a relatively reasonable choice.

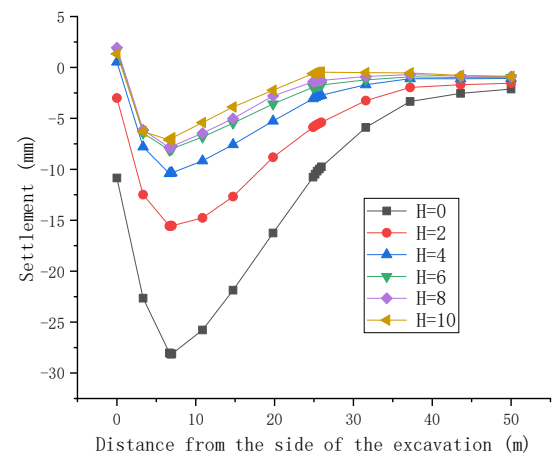

Fig. 13. The influence of depth on settlement

Figure 13 shows the relationship between settlement and the reinforcement depth $\mathrm{H}$ of the passive zone. It can be seen that when the reinforcement depth increases from $\mathrm{H}=0 \mathrm{~m}$ (no reinforcement) to $\mathrm{H}=4 \mathrm{~m}$, the settlement decreases significantly, from $25 \mathrm{~mm}$ to $10.5 \mathrm{~mm}$, which is a decrease of $14.5 \mathrm{~mm}$. When $\mathrm{H}$ increases from $4 \mathrm{~m}$ to $10 \mathrm{~m}$, the settlement decreases, but the amount of decrease is relatively small, only from $10.5 \mathrm{~mm}$ to $7 \mathrm{~mm}$, which is a decrease of $3.5 \mathrm{~mm}$. Considering the settlement, $\mathrm{H}=4 \mathrm{~m}$ is a reasonable choice.

\section{Conclusion}

Within a certain range, as the cohesive force or secant modulus or reinforcement width or depth of the reinforcement area increases, the lateral displacement and settlement outside the pit will decrease. But when it exceeds a certain range, the decreasing trend becomes very slow.

With the increase of the four parameters of the reinforcement zone, bending moments in opposite directions appear below the bottom of the excavation. Moreover, the value of the bending moment is getting larger and larger. Therefore, considering the force, it is not that the wider and deeper the reinforced zone is, the more advantageous is.

\section{References}

1. Liu, G.B., Wang, W.D. (2009) Excavation engineering handbook. China Architecture and Building Press, Beijing

2. Chen, P.F., Gong, X.N., Liu, N.W. (2014) Effect of curtain's role in retaining on deformation of deep excavations. Chinese Journal of Geotechnical Engineering, 36(11): 254-258.

3. MA, Y., Qu, R.F., Zhou, X.T. (2012) Effects of reinforcement parameters in passive zone of excavations on lateral deformation of supporting structures. Chinese Journal of Geotechnical Engineering, 34(S1): 190-196.

4. ZHENG, J.J., ZHANG, R.J., DING, L.Y. (2010) Displacement control effects and parameter analysis of passive zone improvement of foundation pits. Chinese Journal of Rock Mechanics and Engineering, 29(5): 1042-1051.

5. Liu, Y., Li, J.P. (2012) Effect of reinforcement of deep mixing piles on deformation of ultra-deep excavation in passive zone. Chinese Journal of Geotechnical Engineering, 34(11): 465-469.

6. DUAN, H.L. (2006) Investigation of the effect of reinforcement inside the pit on foundation pit deformation. Soil Engineering and Foundation, 20(3): 68-69. 